\title{
e-3Cs: A Research-Based Model for Effective Digital Learning for K-6 Schools
}

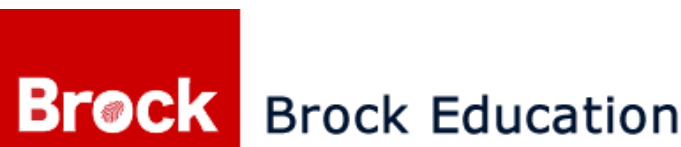

A journal of educational research and practice 2020 Vol. 29 (2) 24-29

https://journals.library.brocku.ca/brocked

\author{
Candace Figg ${ }^{1 *}$, Chunlei Lu ${ }^{1}$, Olivia Lu ${ }^{1}$, Keith Crawford ${ }^{2}$ \\ 1 Brock University \\ 2 District School Board of Niagara
}

\begin{abstract}
Due to the COVID-19 pandemic, teachers in Ontario were thrust into a new teaching situation at the end of the 2019-2020 school year for which few were prepared. To address the need for guidance in transitioning to distance teaching, we offer the e-3Cs model, a research-based framework with flexible elements essential for promoting optimum distance interactions for K-12 learning, more specifically applied to younger learners (K-6). Serving as a tool for designing age-appropriate digital instruction while honouring and caring for affective domain needs of students, the model provides the necessary support for teachers in the purposeful design of digital learning communities.

Keywords: online learning, instructional design, digital learning, distance teaching, $\mathrm{K}-6$ learning

* candace.figg@brocku.ca
\end{abstract}


The recent COVID-19 pandemic in Ontario has forced K-6 teachers to quickly adjust to instructing and supporting students entirely online. Many teachers have experienced mixed success. Some reported to us concerns about low student engagement, lack of accountability, and a lower quality of student work, when compared to their students' performance in a faceto-face ( $\mathrm{f} 2 \mathrm{f}$ ) classroom setting. Instructors felt frustrated with their own teaching performances and were overwhelmed by the abundance of electronic tools. Lacking the institutional support necessary to make the transition, teachers were finding it difficult to support struggling students.

Our K-6 colleagues have been asking those of us who research best practices for teaching-ata-distance for guidance: What are effective practices for engaging students and building the most productive digital learning community possible, even for the youngest learner? Few learning theories have considered the young learner $(\mathrm{K}-6)$ in the distance classroom situation where all instruction and interactions with teachers or other students are virtual, and parents provide the f2f support in the learning process (Donohue et al., 2020).

To address this situation, we present a research-based model of effective digital learning elements to support $\mathrm{K}-6$ teachers in the design and implementation of distance learning. This model draws upon three theoretical foundations of distance learning: (a) the theoretical framework of Anderson's (2011) distance education model encompassing "learners and teachers, and their interactions with each other and with content" (p. 61); (b) Gagne's (1987) nine instructional events (see Culatta \& Kearsley, 2020); and (c) Farrell et al.'s (2017) use of the collaborative community to provide socio-emotional support to online learners. The following is a detailed elaboration of the model with the elements from online learning theories structured for optimum learning as enacted through a digital learning collaborative community.

\section{The Learning Community}

An emerging trend among many $\mathrm{K}-6$ teachers is the use of virtual classrooms to simulate the $\mathrm{f} 2 \mathrm{f}$ classroom; therefore, the model proposed here (see Figure 1 ) is intended to be a flexible tool that supports teachers in the design, construction, and implementation of K-6 distance learning environments. By attending to each of the elements in the model, the teacher ensures that their virtual classroom is an effective, engaging learning community.

In this paper, we consider the example of a third grade teacher who, to promote a learning community, builds a virtual classroom - such as those created using Bitmoji cartoons as a homepage with links to assignments, calendars, and typical activities found in a $\mathrm{f} 2 \mathrm{f}$ classroom. For the young learner, the concept of community and a sense of belonging is at the heart of learning (Sapon-Shelvin, 2010) and is paramount for social and emotional growth (Battistitch et al., 1999). However, without the $\mathrm{f} 2 \mathrm{f}$ interaction in the physical classroom, developing that 
feeling of community in digital environments is a formidable task. Especially for young learners, a strong teacher presence is essential-just as it is in the $\mathrm{f} 2 \mathrm{f}$ classroom-as are activities that build upon the unique strengths of students, invite participation, and present content in various modalities as frequently as possible (Wilson, 2014).

\section{Figure 1}

\section{e-3Cs: A Research-Based Model for Effective Digital Learning for $K-12$ Schools}

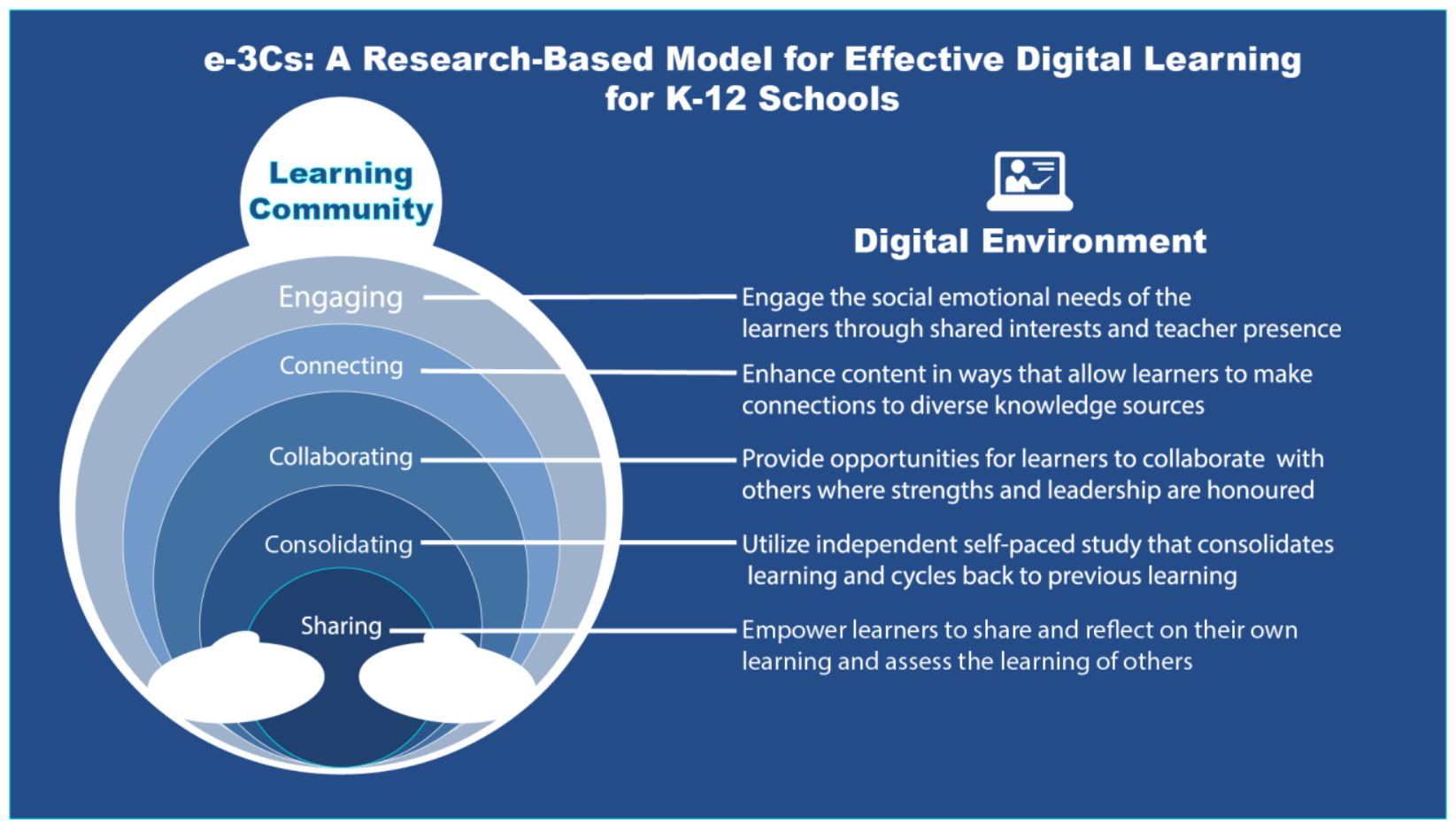

The diagram shown in Figure 1 illustrates how a learning community ensures that teacher presence and appropriate activities are the centrepiece of such a virtual learning environment.

\section{Engaging}

In Figure 1, the largest concentric circle of experiences the learner should have within the learning community is engaging. Engaging is foundational, embracing all other elements in the model because engagement of the learner is an ongoing consideration of the teacher. Many students associate technology with fun, play, and leisure, and have positive feelings about digital learning activities. Our third grade teacher may capitalize on this positive attitude by designing learning experiences and spaces that are fun, humorous, and exciting. Often, this is accomplished by weaving student interest, voice, and passion into the design of learning activities. Engagement is also developed by respecting students' curiosity, play, and humour when making choices about content and design of the digital environment-students feel honoured and respected as co-creators of the environment (Borup et al., 2014). 


\section{Connecting}

In order to maintain wellness and meaningful learning, we need ways to connect with others and the world around us. Learning happens through building a network of diverse connections (Siemens, 2005) and through social contexts (Vygotsky, 1978). In the online classroom, there are multiple connections that should be established, of which the most important to this model are: teacher-student, student-student, student-content, student-local community, teacher-local community, teacher-student home, and student-home (Anderson, 2001; Farrell et al., 2017). Connecting is the bulk of teacher and student work in the model. When $\mathrm{K}-6$ teachers are thinking about how to design experiences that support the creation of these networks and connections, a design approach that is empathic towards the child learner should take precedence. Our third grade teacher would ensure connections by designing areas in the virtual classroom for checklists for assignments, virtual tours led by community experts, tutorials for parents to help their children, school community information, and multiple ways to access the teacher.

\section{Collaborating}

In collaborating, students are required to use language in creative ways to accomplish a shared goal. Through collaboration, students grow to understand the importance of using language to communicate with, and tap into, peer-tutors and knowledge experts to enhance their learning (Siemens, 2005). Our third grade teacher would encourage collaboration by purposefully creating spaces and opportunities where students can work together, problem solve, and support one another. Breakout rooms and online interactive whiteboards are collaborative environments where students complete learning tasks with each other without continually relying on the teacher (Farrell et al., 2017).

\section{Consolidating}

Consolidation refers to the learning act where knowledge is internalized, secured, and strengthened through synthesizing experiences, memories, and knowledge sources to build understanding (Jensen \& McConchie, 2020). For our third grade teacher, consolidating would mean including activities such as virtual exit tickets, Jamboard postings, or contributing to class forums. Even though there is a strong emphasis on the individual learner experience, we recognize that collaboration can provide opportunities for consolidation through which students consolidate personal knowledge by questioning their own perspective or reinforce what they already know in relation to what others know.

\section{Sharing}

Sharing is an element in this model because it provides opportunities for students to appreciate their progress. Sharing imperfect products of learning are just as valuable as successful ones 
because students see "work" as an ongoing process that can be refined and improved (Hiebert et al., 1997). Fostering positive attitudes toward the students' "work" in digital environments requires the teacher to engage students in sharing activities where students feel accommodated and at ease, and where comprehensive evidence of learning is shared by students (Farrell et al., 2017). Our third grade teacher encourages sharing by using the "share-the-screen" capability of videoconference tools to promote sharing-time interactions, or incorporating collaborative slideshows where students post "work-in-progress" pictures and participate in virtual gallery walk discussions.

\section{Conclusion}

In proposing a model with essential elements to serve as a framework for quality $\mathrm{K}-6$ distance learning, we hope to provide research-based guidance for the purposeful design of online learning environments, and offer an effective tool for designing age-appropriate digital instruction while honouring and caring for the students' affective domain-from a distance.

\section{References}

Anderson, T. (Ed.). (2011). The theory and practice of online learning (2nd ed.). AU Press.

Battistich, V., Watson, M., Solomon, D., Lewis, C., \& Schaps, E. (1999). Beyond the three R's: A broader agenda for school reform. Elementary School Journal, 99(5), 415-432. https:/ / doi.org/10.1086/461933

Borup, J., West, R. E., Graham, C. R., \& Davies, R. S. (2014). The adolescent community of engagement framework: A lens for research on K-12 online learning. Journal of Technology and Teacher Education, 22(1), 107-129. https:/ /www.learntechlib.org/primary/p/112371/

Culatta, R., \& Kearsley, G. (2020). Conditions of learning (Robert Gagne). InstructionalDesign.org. https://www.instructionaldesign.org/theories/conditionslearning/

Donohue, C., Johnson, A., Lucas, P., Lynd, C., Mukerjee, J., \& Thouvenelle, S. (2020, May 1). Distance learning and early childhood education. Head Start/ECLKC. https://eclkc.ohs.acf.hhs.gov/professional-development/article/distance-learning-earlychildhood-education

Farrell, J., Manion, C., \& Rincon-Gallardo, S. (2017). Reinventing schooling: Successful radical alternatives from the Global South. In K. Bickmore, R. Hayhoe, C. Manion, K. Mundy, \& R. Read (Eds.), Comparative and international education (pp. 59-87). Canadian Scholars.

Gagne, R. M. (Ed.). (1987). Instructional technology foundations. Lawrence Erlbaum. 
Hiebert, J., Carpenter, T. P., Fennema, E., Fuson, K. C., Wearne, D., Murray, H., Olivier, A., \& Human, P. (1997). Making sense: Teaching and learning mathematics with understanding. Heinemann.

Jensen, E. P., \& McConchie, L. (2020). Brain-based learning: Teaching the way students really learn (3rd ed.). Corwin.

Sapon-Shelvin, M. (2010). Because we can change the world: A practical guide to building cooperative, inclusive classroom communities ( $2 \mathrm{nd}$ ed.). Corwin.

Siemens, G. (2005). Connectivism: A learning theory for the digital age. International Journal of Instructional Technology \& Distance Learning, 2(1).

http://www.itdl.org/Journal/Jan_05/article01.htm

Vygotsky, L. S. (1978). Mind in society: The development of higher psychological processes. Harvard University Press.

Wilson, L. (2014). Partnerships: Families and communities in early childhood. Nelson. 